\title{
Therapeutic vaccination for HPV induced cervical cancers
}

\author{
Joeli A. Brinkman ${ }^{\mathrm{a}}$, Sarah H. Hughes ${ }^{\mathrm{b}}$, Pamela Stone ${ }^{\mathrm{b}}$, Angela S. Caffrey ${ }^{\mathrm{b}}$, Laila I. Muderspach ${ }^{\mathrm{b}}$, \\ Lynda D. Roman ${ }^{\mathrm{b}}$, Jeffrey S. Weber ${ }^{\mathrm{c}}$ and W. Martin Kast ${ }^{\mathrm{a}, \mathrm{d}, *}$ \\ ${ }^{a}$ Norris Comprehensive Cancer Center, University of Southern California, Keck School of Medicine, Los Angeles, \\ CA, USA \\ ${ }^{\mathrm{b}}$ Department of Obstetrics and Gynecology, University of Southern California, Keck School of Medicine, Los \\ Angeles, CA, USA \\ ${ }^{\mathrm{c}}$ Department of Medicine, University of Southern California, Keck School of Medicine, Los Angeles, CA, USA \\ ${ }^{\mathrm{d}}$ Department of Molecular Microbiology and Imunology, University of Southern California, Keck School of \\ Medicine, Los Angeles, CA, USA
}

\begin{abstract}
Cervical Cancer is the second leading cause of cancer - related deaths in women worldwide and is associated with Human Papillomavirus (HPV) infection, creating a unique opportunity to treat cervical cancer through anti-viral vaccination. Although a prophylactic vaccine may be available within a year, millions of women, already infected, will continue to suffer from HPV-related disease, emphasizing the need to develop therapeutic vaccination strategies. A majority of clinical trials examining therapeutic vaccination have shown limited efficacy due to examining patients with more advanced-stage cancer who tend to have decreased immune function. Current trends in clinical trials with therapeutic agents examine patients with pre-invasive lesions in order to prevent invasive cervical cancer. However, longer follow-up is necessary to correlate immune responses to lesion regression. Meanwhile, preclinical studies in this field include further exploration of peptide or protein vaccination, and the delivery of HPV antigens in DNA-based vaccines or in viral vectors. As long as pre-clinical studies continue to advance, the prospect of therapeutic vaccination to treat existing lesions seem good in the near future. Positive consequences of therapeutic vaccination would include less disfiguring treatment options and fewer instances of recurrent or progressive lesions leading to a reduction in cervical cancer incidence.
\end{abstract}

Keywords: Human papillomavirus (HPV), therapeutic vaccination, clinical trials

\section{Introduction}

Cervical cancer, the second most common cause of cancer-related deaths in women worldwide, is highly associated with Human Papillomaviruses (HPV) infection of the anogenital region. HPV is detected in $99.7 \%$ of cervical carcinomas [104]. World-wide approximately 510,000 new cases and 288,000 deaths due to cervical cancer are reported annually [3]. In the Unit-

* Corresponding author: W. Martin Kast, Ph.D., University of Southern California, 1501 San Pablo Street, ZNI 245, MC 2821, Los Angeles, CA 90089-2821, USA. Tel.: +1 323442 3870; Fax: +1 323442 4433; E-mail: mkast@usc.edu. ed States Papanicicoloau (Pap) smear screening has reduced cervical cancer mortality by $70 \%$ in the last 50 years [63]. However, despite the availability of Pap smear screening, approximately 13,000 new cervical cancer cases and 4,500 deaths occur yearly making cervical cancer the tenth most common cancer in women in the US $[1,10]$.

Approximately $30-50 \%$ of the general population is positive for HPV DNA in the anogenital region making HPV one of the most common sexually transmitted infections of viral origin. There are over 30 known HPV types that infect the anogenital region [18]. These types are classified as being low, intermediate or high-risk based on their in-vitro ability to interact with cell cycle 
Table 1

Clinical trial phases

\begin{tabular}{|c|c|c|c|}
\hline Phase I & Phase II & Phase III & Phase IV \\
\hline $\begin{array}{l}\text { Involve a small number of peo- } \\
\text { ple (20-80), are the first studies } \\
\text { on humans. The goal is to see } \\
\text { if the treatment is safe, if it has } \\
\text { harmful side effects, and how } \\
\text { it is best administered. If the } \\
\text { results are positive, researchers } \\
\text { move on to phase II }\end{array}$ & $\begin{array}{l}\text { A small number of participants } \\
(100-300) \text { are used to determine } \\
\text { the effectiveness of a therapeutic } \\
\text { agent. The major outcomes can be } \\
\text { clinical and/or immunological re- } \\
\text { sponses. If benefit is demonstrat- } \\
\text { ed, it moves on to phase III }\end{array}$ & $\begin{array}{l}\text { A large number of partipants } \\
(1,000-3,000) \text { participants at dif- } \\
\text { ferent hospitals and research cen- } \\
\text { ters are utilized to confirm the } \\
\text { treatments effectiveness, monitor } \\
\text { side effects, and compare it to } \\
\text { commonly used treatments, and } \\
\text { collect information that will al- } \\
\text { low the treatment to be used safe- } \\
\text { ly. Most phase III studies are ran- } \\
\text { domized and blinded trials }\end{array}$ & $\begin{array}{l}\text { Post marketing studies after the } \\
\text { treatment has received FDA ap- } \\
\text { proval delineate additional in- } \\
\text { formation including the drug's } \\
\text { optimal use and cost benefit } \\
\text { analysis }\end{array}$ \\
\hline
\end{tabular}

Adapted from: $[4,5,7]$.

proteins and clinical association with causing cervical cancer. Low risk HPV types like 6 and 11 are associated with causing the sexually transmitted disease of genital warts [40]. High-risk HPV types, like 16, 18, 31, and 45 are closely associated with anogenital malignancies including penile, anal, vaginal and vulva carcinomas and have been implicated in the etiology of most, if not all cervical cancers with high risk types HPV 16 and 18 accounting for nearly $70 \%$ of cases [62]. Interestingly, while HPV infection is highly prevalent in the general population, the infection is asymptomatic in most people largely due to host immune system's ability to control the virus and usually does not lead to cancer [62]. In contrast to many other cancers, the fact that cervical cancer is highly associated with a viral infection and that host immune responses control the infection in a majority of infected subjects, opens the possibility of vaccination against HPV viruses as a unique opportunity to either prevent or treat cervical cancer. A prophylactic vaccine for cervical cancer may be available within the next year. However, prophylactic vaccination will have no effect on millions of women already infected with HPV or women who will become infected before the vaccine is available. Additionally, even with conventional treatments mortality from cervical cancer is approximately $40 \%$ [22] and conventional treatments for HPV-related pre-malignant lesions can effect female reproduction and cause discomfort. Also HPV associated pre-malignant lesions have a high rate of recurrence, signifying the necessity to develop effective therapeutic vaccines to treat existing disease. The purpose of this article is to discuss therapeutic anti HPV strategies that are currently in clinical trials, a definition of clinical trial stages appears in Table 1, and to indicate innovations in pre-clinical trials of therapeutic vaccines to treat cervical cancers.

\subsection{HPV Biology}

HPV is a virus with icosahedral symmetry and 72 capsomeres, arranged in a pentameric structure surrounding the genome [15]. The genetic information of HPV viruses is encoded in a double stranded, circular genome that is approximately $8 \mathrm{~Kb}$ long. The genome can be divided into three major regions: early genes, late genes, and control genes [91].

The lifecycle of HPV encompasses infection of the basal epithelium and is closely linked to keratinocyte differentiation [108]. The basal epithelial layer is the only layer in the epithelium that is actively dividing [72] and minor trauma to the outer epithelial layer is probably required in order for the virus to reach this layer and initiate infection [67]. Once infection is initiated in the basal cell layer, the viral genome is maintained as a low copy episome. As the keratinocyte undergoes differentiation, viral gene expression and genome amplification both increase until late gene expression of the L1 and L2 capsid forming proteins occurs in terminally differentiated superficial cells [94]. Another form of infection is non-permissive, transformable infection in which viral replication does not occur. In this situation, viral DNA persists as either an extrachromosomal element or becomes integrated into the host cell chromosome at a random site [80]. Viral integration into the host cell DNA is believed to be a necessary step in cellular transformation in mucosal HPV.

E6 and E7 are the major oncogenic proteins involved in HPV carcinogenesis. Both proteins interfere with the normal mechanisms of cell cycle control [97]. HPV types that are low risk for causing cancer have weak interactions with the cell cycle control components, p53 and $\mathrm{Rb}$, whereas high-risk types have stronger binding affinities for these cellular components. The E6 protein of high-risk HPV types forms a complex with the cellular protein E6 associated AP or E6 AP. The E6 
AP complex then binds to and degrades p53 through ubiquitin-directed proteolysis [49,71]. P53 is essential for DNA repair as it mediates either G1 growth arrest or apoptosis in response to DNA damage in the cell. Degradation of p53 would result in the lack of cell cycle control leading to the accumulation of mutations and in genetic instability [40]. The E7 protein of high-risk HPV types binds the retinoblastoma tumor suppressor protein $(\mathrm{pRb})$ with higher affinity than low risk types. The binding of the E7 protein to $\mathrm{pRb}$ causes $\mathrm{Rb}$ to release the transcription factor E2F. This results in activation of certain E2F dependent genes required for DNA synthesis and cell cycle control $[49,71]$. The effect is deregulated cell cycle control and uncontrolled cellular proliferation. When the virus integrates into the host chromosome, the E1/E2 genes, which regulate E6 and E7 protein production, are interrupted with a resultant increase in both of these oncogenes. Given that expression of E6 and E7 is required for maintenance of the transformed state [103] and expression levels are higher in transformed cells [23,34,40], expression of the oncoproteins and is not likely to be lost due to immunological pressures. This makes the E6 and E7 oncoproteins logical targets for HPV-specific therapeutic vaccine approaches.

\subsection{HPV Immunology}

In patients having early stage cervical carcinoma and HPV induced CIN lesions, cytotoxic T cell (CTL) responses have been demonstrated against HPV-16 and HPV-18 [36,73,85]. In addition, T helper cell responses directed against HPV-16 E6 and E7 have been detected in patients with abnormal cervical cytology [29, $30,56,68,105,106]$. Epidemiological studies involving screening cohorts for the presence of HPV antibodies indicate that neutralizing conformational IgG antibodies directed toward the major capsid antigen (L1) occur in a majority in people having past or current HPV infection. However, these antibody titers are generally low and type specific. Thus antibodies to one HPV type are not protective for other HPV types [42]. These studies may indicate that while effective antiviral immunity is generated in a majority of HPV infected individuals, this immunity may develop too late or be of too low of magnitude to prevent the development of cancer in some individuals. However, these data do indicate that through enhancement of the host's immune response via vaccination, infection with certain high risk types can be prevented or even treated.
Effective eradiation of virally infected cells is generally mediated by a Th1 type immune response characterized by the presence of activated CTL and CD4+ $\mathrm{T}$ helper cells. Helper $\mathrm{T}$ cells aid in viral eradication and tumor ablation by helping to activate and maintain CTL-mediated responses to tumor antigens through the induction of Th1 cytokines like IFN-gamma. CTL are considered the major eradicators of both tumor and virally infected cells in the adaptive immune response. Target cells are identified by CTL as a result of the presentation of aberrant or "non-self" antigens, typically 8-10 amino acids in length and complexed with Major Histocompatibility Complex (MHC) class I molecules on the cell surface of a majority cells in the body. "Self" proteins are also presented in the context of MHC I molecules and this allows the cells of the immune system to distinguish between "self" and "non-self" antigens. Aberrant, "non-self" and "self" antigens are endogenous proteins that are degraded by the proteasome complex in the cytosol before they are transported by the TAP transporter into the endoplasmic reticulum for complexing with MHC class I molecules and then transported to the cell surface through the Golgi Complex [86]. Helper T cells interact with professional antigen presenting cells (APC), which present viral and tumor antigens through the MHC II pathway [86]. Viral antigens or components of tumor cells that are present in the extracellular spaces can become ingested by APC through endocytosis and subsequently degraded into 12-15 amino acid peptides in endosomal vesicles [88]. Vesicles containing peptides fuse with vesicles containing newly synthesized MHC class II molecules in the cytosol. The MHC class II molecules and the peptide antigen associate and then the bound peptide is transported to the cell surface of the APC [55]. This process is known as exogenous antigen presentation and unlike MHC class I presentation is restricted to professional APC such as B lymphocytes, macrophages, Langerhans cells (LC), and dendritic cells (DC).

Immature LC and DC are professional antigen presenting cells that specialize in antigen capture in the periphery. Immature DC reside in the dermis, whereas immature LC are found in the epidermis of the skin and in the epithelial layers of all mucosa [12,37]. In the genital tract, HPV infection is initiated in basal epithelial cells and LC are believed to pick up HPV particles and cross present these antigens to naïve T cells [99]. In the process, the LC should undergo maturation to initiate an adaptive immune response. However, the local cytokine environment in which LC encounter HPV antigens contributed to by keratinocytes which secrete 
TGF-beta, and IL-10 [54] may result in an APC that is polarized to Th-2 type immunity which may result in a relatively ineffective response against solid tumors and HPV infected cells [99]. Conversely, under conditions of inflammation, keratinocytes can produce proinflammatory cytokines which can promote a Th1 type immune response leading to presentation of viral antigens by mature LC and the generation of an effective immune response against HPV infection [99]. The effects of the local cytokine environment upon primary introduction of HPV antigens may explain why some women resolve HPV infection while others progress. An interesting study by Fausch et al. demonstrated that while HPV virus-like particles (VLP) can activate DC they do not do not activate Langerhans cells [37, 38] indicating an intriguing immune escape mechanism employed by HPV [39]. DCs have emerged as one of the best stimulators of naïve T cells [37]. DC have a high density of MHC and co-stimulatory molecules and they efficiently process exogenous antigens through the MHC class I pathway in order to stimulate naïve CD8+ $\mathrm{T}$ cells through the process of cross presentation [86]. Targeting HPV antigens to DC by vaccination, resulting in activation and a subsequent Th1 response, as opposed to antigen capture by LC in a natural infection may overcome HPV-induced immune escape and lead to lesion regression in HPV infected subjects.

\section{Therapeutic vaccines}

While prophylactic vaccination strategies aim to prevent initial infection with the HPV virus by inducing a neutralizing antibody response toward the L1 and the $\mathrm{L} 2$ capsid antigens, therapeutic vaccination against HPV attempts to induce strong CTL and Helper T cell responses to HPV antigens, such as the E6 and E7 oncoproteins, which unlike the $\mathrm{L} 1$ and $\mathrm{L} 2$ capsid antigens are expressed in pre-cancerous and cancerous tissue. In particular the E6 and E7 oncoproteins contain epitopes that are processed and presented in association with the HLA-A2 MHC class I molecule [96]. MHC class I restricted peptide epitopes have been generated for the E6 and E7 protein of HPV 16 and 18 [57,87] that have demonstrated immunogenicity in both human and animal models $[9,83]$. For these reasons peptides generated from the E6 and E7 protein have been used extensively in clinical trials attempting to treat HPV associated cancers.

\subsection{Peptide and protein-based vaccines}

A phase I clinical trial sought to examine the efficacy of multiple administrations of an HLA-A*0201restricted HPV-16 E7 lipopeptide vaccine linked to the non-specific helper peptide PADRE in twelve women with refractory cervical or vaginal cancer [96]. Four subcutaneous injections (s.c) of the E7 86-93 lipopeptide were given at three week intervals. Five of seven patients that were evaluable after two vaccinations and $2 / 3$ patients that were evaluable after all four vaccinations demonstrated an E7 peptide specific CTL response as determined by IFN- $\gamma$ release assay. However, no clinical responses were associated with vaccination in these studies.

Another phase I-II clinical trial utilized two HPV16 E7 peptides and the PADRE helper peptide delivered in incomplete Freund's adjuvant (IFA) to perform a dose escalation study in 19 HLA-A*0201+ patients with HPV-16+ cervical carcinoma [101]. Successive patient groups received $100 \mu \mathrm{g}, 300 \mu \mathrm{g}$, or $1000 \mu \mathrm{g}$ of each peptide s.c. every three weeks for four vaccinations. Utilizing radiological evaluation, two patients demonstrated stable disease for one year after vaccination and two patients demonstrated tumor regression after vaccination and subsequent chemotherapy treatments. All other patients experienced progressive disease. Immunohistochemical evaluation of skin biopsies taken from the site of vaccination demonstrated an influx of $\mathrm{CD} 8+, \mathrm{CD} 4+$, and $\mathrm{CD} 3+\mathrm{T}$ cells in three patients analyzed. A large portion of the patients in the study demonstrated lymphopenia both before and after vaccination, indicating that this study population was fairly immunocompromised due to the nature of their disease. Immunological analysis from peripheral blood mononuclear cells measured after vaccination indicated that there was no E7 peptide-specific CTL induction in these patients at any dose [84] perhaps indicating that these patients were too advanced to benefit from peptide immunization.

Another phase I trial was conducted in women with high-grade cervical or vulvar intraepithelial neoplasia who were HLA-A2 and HPV-16 positive [70]. Eighteen patients were treated with four vaccinations given three weeks apart with escalating doses of the E7 peptide 12-20 in incomplete Freund's adjuvant (IFA). Starting with the eleventh patient, the E7 peptide 86-93 linked to the PADRE helper peptide with a covalently linked lipid tail was added to the vaccine regimen. Three out of 17 patients demonstrated complete and 9/17 demonstrated partial regression of dyplastic le- 
sions. Although T cell frequencies remained the same, $6 / 6$ patients tested by immunohistochemical staining demonstrated an increase in DC infiltrates in dysplastic tissue. Although positive delayed type hypersensitivity (DTH) responses were not detected in any patients after vaccination, E7 peptide specific cytotoxic T lymphocytes (CTL) responses were detected from PBMC in 10/16 patients. Lastly, while Pap smears turned out to be negative, in situ RNA hybridization revealed that all biopsy specimens were positive for HPV viral RNA after vaccination, although at a much reduced level. Thus, while the therapeutic vaccine in this study was able to effect complete regression in three patients and partial regression in nine others, demonstration of viral RNA in biopsy specimens post vaccination may be an indication of insufficient follow-up time in order to demonstrate complete viral clearance.

Although in a majority of HPV peptide based vaccine trials an HPV specific CTL response has been detected in some patients, tumor regression has been minimal and these CTL responses do not correlate with clinical outcome. An explanation for the lack of correlation between peptide specific $\mathrm{T}$ cell responses and clinical outcome may involve the general state of the patients' immune system such that more advanced stage cancer patients tend to have decreased immune function that correlates with stage of disease. Many of the studies discussed above included patients with advanced stage cancers. Obviously, it is necessary to examine peptide or protein based vaccination in patients with early stage cancers or even pre-invasive lesions in order to assess whether in vitro immune reactivity can predict tumor regression or prevent disease progression. One such clinical trial was recently conducted in women having CIN 1-3 lesions [47]. The vaccine agent was a fusion protein (PD-E7) containing mutated HPV-16 E7 protein conjugated to protein D of Haemophilus influenzae and delivered intramuscularly with AS02B adjuvant. Five out of seven patients in the study demonstrated significant increases in IFN- $\gamma$ responses and all vaccinated patients had significant titers of E7 antibodies. However, clinical responses were not correlated with immune responses in this study and the investigators suggested that the efficacy of this agent needs to be further examined in a larger cohort of CIN patients having a high and persistent HPV viral load. Similarly, a recombinant fusion protein consisting of heat shock protein (Hsp 65) from Mycobacterium Bovis BCG and the E7 protein of HPV 16 was developed to treat HPV related diseases. A recent Phase II clinical trial utilizing this agent demonstrated high statistical significance for lengthening the interval between de-bulking surgeries for patients with recurrent respiratory papillomatosis (RRP). The results from a separate phase II clinical trial demonstrated that HspE7 is likely active in anal intraepithelial neoplasia (AIN) in converting most patients from high grade to low grade squamous intraepithelial lesions within 3-6 months of starting therapy. An interesting finding in this study was that vaccination with this agent also caused regression of anogenital genital warts in several patients [46]. However, a recent adjunct of this trial involving 133 patients [8], designed to confirm previous results, indicated that the drug exceeded the treatment effect, but the anticipated placebo effect doubled as estimated by experts through studies of natural history, and thus there was no difference between drug and placebo. In this study there was a highly discordant level of interpreted degree of dysplasia between separate pathologists and thus additional measurements of HPV, such as viral load, need to be evaluated in Phase III anal dysplasia trials. The use of this agent to treat 21 women with HPV-related CIN lesions was shown to induce a $40 \%$ response rate within 8 weeks. However, Elucidation of the full extent of the clinical benefit will require long-term followup $[2,8]$. Additional pre-clinical studies investigating the use of heat shock protein 70 from Mycobacterium tuberulosis fused to HPV-16 E6 and E7 mutated proteins has shown regression of established lung metastases in mice [3] suggesting that the use of heat shock proteins as adjuvants requires further investigation.

Two recent clinical trials have examined therapeutic HPV protein-based vaccine strategies in subjects that do not have HPV related disease. A phase I clinical trial was recently conducted in 40 healthy volunteers [31]. The vaccine agent utilized for these studies, TA-CIN, is a single fusion protein of HPV-16 L2, E6 and E7 proteins and it was administered without adjuvant intramuscularly in three doses. The results indicated that E6 and E7 specific T cell immunity was induced in 8/11 evaluable subjects at the highest dose as well as antibody and $\mathrm{T}$ cell proliferative responses. A similar recombinant bacterial fusion protein of HPV-16 E6 and E7 has been made and delivered in ISCOMATRIX ${ }^{\circledR}$ adjuvant intramuscularly to 42 healthy volunteers in a Phase I clinical trial. After three injections of the vaccine agent, measurable $\mathrm{T}$ cell responses were detected in $80 \%$ of vaccinated subjects and all vaccine recipients demonstrated an HPV-16 E6/E7 antibody response [8, 14]. A follow-up study utilized this agent in 31 patients having CIN lesions and demonstrated good immune responses and a reduction in viral load for patients who 
were HPV-16+ [43]. The preliminary findings in these trials are indeed encouraging but require further evaluation in order to fully access clinical efficacy.

Pre-clinical research utilizing peptide based vaccines has shifted to the examination of proteins [60] or peptides generated from other early genes of HPV that are expressed in cervical cancers delivered with bacterial adjuvants such as CpG oligodeoxynucleotides [19] and to the administration of long peptides or whole protein vaccines as mentioned above. The trend of utilizing long peptides and whole protein is attributable to the desire to allow presentation of more CTL epitopes and $\mathrm{T}$ helper epitopes. As mentioned previously, $\mathrm{T}$ helper cells are necessary to enhance CTL mediated tumor killing and for the generation of memory responses. One such strategy was recently employed in a preclinical cottontail rabbit papillomavirus model of recurrent respiratory papillomatosis (RRP). In the study, long over-lapping peptides containing CTL and helper epitopes were able to significantly reduce latent infection and control wart growth in cottontail rabbit papillomavirus infected rabbits [98]. A different preclinical study demonstrated complete tumor regression in mice by utilizing adenylate cyclase (CyaA) of Bordetella pertussis, which is able to target DC through its interaction with the CD11b/CD18 integrin, conjugated to HPV-16 E7 protein [81]. Another preclinical study examined prime-boost vaccination with a 35 amino acid HPV-16 E7 peptide that included both CTL and T helper epitopes administered with oligodeoxynucleotide- $\mathrm{CpG}$ as adjuvant to activate DC in C57BL/6 mice and compared their results to mice that were immunized with a minimal E7 CTL epitope [109]. The results demonstrated that a more vigorous CTL response and enhanced tumor eradication was seen when vaccinating with the long peptide as compared to vaccination with the minimal CTL epitope. The results of these studies are encouraging and indicate the need for further investigation into vaccination with long peptides and whole proteins and additional exploration into the use of prime boost strategies to vaccinate with peptide-based agents.

\subsection{Dendritic cell vaccination}

Another approach to therapeutic vaccination in cancer patients has been peptide or protein pulsing of autologous DC and then returning these dendritic cells to the patient. DC are a potent APC type with the ability to stimulate and maintain immune responses when pulsed with antigens [13,95]. A recent clinical trial was conducted in 15 stage IV cervical cancer patients uti- lizing autologous DC pulsed with recombinant HPV16 or HPV-18 E7 oncoproteins. Although, a specific cellular immune response was seen in 4/11 patients and a specific antibody response was seen in $3 / 11$ patients, no clinical responses were observed [41]. A similar study conducted in four terminal cervical cancer patients utilized DC pulsed with HPV-16 and HPV-18 E7 proteins in adjunct to rIL-2 treatment. In this study, specific humoral and cellular CD4+ T cell responses to the $\mathrm{E} 7$ vaccine were detected in two patients and increased numbers of E7-specific IFN-gamma secreting $\mathrm{CD} 8+\mathrm{T}$ cells were detected in all patients after vaccination. However, no objective clinical responses were observed [89]. The culmination of both of these reports may indicate that more potent adjuvants or even adjunct vaccination may be necessary to treat cervical cancer patients at such a late state. An advantage to using full length protein over single peptides is the possibility of presenting more CTL epitopes for immune recognition, however, single peptides are cheaper to prepare. To this end, a recent study described a new HPV-16 E6 52-61 B57 HLA class I peptide in which T cell clones specific for this peptide were also able to recognize analogous epitopes from HPV types 35, 39, 45, 51, and 73. However, the efficacy of this peptide delivered in DC, administered to HLA-B57 cancer patients, has yet to be determined [59]. Strategies to enhance the potency of DC based therapeutic vaccine delivery include: DC transfected with a rearranged HPV-16 E7 DNA vaccine [79] and DC loaded with HPV peptides and transfected with HPV small interfering RNA targeting the Bak and Bax anti-apoptotic proteins in order to prolong DC life and thus enhance immunity [77]. Even though delivery of peptide or protein based vaccines by pulsing autologous DC with antigen shows promise in tumor immunotherapy, the technique is cumbersome because of the necessity of stimulating the patient's DC ex vivo.

\subsection{DNA vaccines}

Recent efforts in the field of HPV tumor immunotherapy have focused on the delivery of peptides in the form of mini-gene vaccines or naked DNA vaccines. DNA based vaccines are attractive candidates for therapeutic vaccines because of the simplicity of delivery, stability, and overall safety. DNA based vaccines can either stably integrate into the genome or be maintained in an episomal form allowing for extended expression of HPV antigens over a longer period of time than peptide vaccination. Furthermore, administration of DNA based vaccines has been shown to induce both CTL and 
antibody responses to HPV antigens [35]. To date, two phase I clinical trials, assessing the safety of mini-gene administration in the delivery vehicle have taken place. One study examined this vaccine regimen in 12 patients with HPV-16 associated anal dysplasia [61] and a more recent study examined this vaccination strategy in 15 women with CIN 2 or 3 [92]. The ZYC101 vaccination agent utilized for both of these studies consists of bacterial expression plasmid that expresses a segment of the HPV-16 E7 gene which includes several overlapping CTL epitopes and is fused to a secretory leader sequence derived from the HLA-DRA*0101 locus [61, 92]. The construct was delivered to patients with high grade anal dysplasia on a dose escalating scale either by intramuscular (i.m.) injection [61] or i.m. and s.c. injection [92] encapsulated in poly lactide-co-glyolide particles, which enhances delivery to antigen presenting cells [61]. All of the patients utilized in both studies were HLA-A2 and HPV-16 positive. After four i.m. injections at three week intervals, $3 / 12$ patients demonstrated partial regression of anal dysplasia lesions and 10/12 patients demonstrated increased peptide-specific immune responses as determined by direct ELISPOT assay. All ten of these patients maintained heightened immune responses for at least six months and no serious adverse effects were seen [61]. In the study examining women with CIN, three treatments were given at three week intervals and colposcopy was performed at each treatment and at a four month follow-up period. Eleven of 15 women in the study demonstrated peptide - specific $\mathrm{T}$ cell responses as judged by IFN- $\gamma$ release in ELISA assay and five women demonstrated complete regression of cervical lesions. Four of five of the women who regressed developed cervical IgA responses to the E2 protein of HPV-16, suggesting that HPV infected cells are undergoing lysis as a result of immune stimulation due to vaccination and that this is in effect causing epitope spreading of other HPV antigens that are not included in the vaccine formulation [92]. An improved agent, ZYC101a, was recently utilized in a multi-center study involving 127 women with biopsy confirmed CIN $2 / 3$ lesions. Six months after vaccine administration, a higher proportion of vaccinated subjects resolved their lesions than those in the placebo group. However, this effect was most pronounced in subjects who were less than twenty-five years of age [44]. The preliminary results of this study are slightly encouraging; but the study is still ongoing in order to measure the durability of the agent's effect over a longer follow-up period.

Preclinical studies using DNA based vaccine approaches tend to focus on enhancing presentation of
HPV antigens via the MHC class I pathway. Several different approaches have been examined including the attachment of ubiquitin to DNA constructs [66,102], targeting of tumor antigens to centrosomal compartments to enhance MHC class I presentation [52] or the attachment to constructs of calreticulin to target HPV antigens to the MHC I pathway [76,78] optimization of codon usage for enhanced expression and presentation of HPV oncogenes [21,65,66], utilization of modified or duplicated genes to increase the number of available CTL epitopes [16,32,74,75], enhancement of intercellular spreading in order to increase the number of cells expressing antigen [53], or even encoding of a single chain trimer containing b2-microglobulin, $\mathrm{MHC}$ class I heavy chain, and an immunodominant HPV-16 E6 epitope in order to bypass antigen processing and cause stable presentation of E6 antigens [51]. All of these approaches have demonstrated increased antigen presentation and superior tumor eradication in mouse models. However, further examination is necessary in order to determine if these effects can be achieved in humans.

\subsection{Delivery of HPV antigens through viral vectors}

Delivery of HPV antigens, particularly those derived from the E6 and E7 oncogenes, in recombinant viruses poses an attractive approach for therapeutic vaccination. It offers an advantage over peptide immunization in that CTL epitopes can be processed and presented naturally and are delivered more efficiently to target cells and it has an advantage over DNA based vaccines because it increases the efficiency of introducing heterologous genes into target cells [20]. Viruses like vaccinia, the agent utilized to vaccinate against the disease Small Pox, are lytic and extremely immunogenic. The lysis of vaccinia infected cells insures uptake of the HPV antigens and the vaccinia virus acts as an adjuvant to enhance the immune response to the HPV antigens. One vaccine based on this scheme is the TA-HPV vaccine which was recently examined for immunogenicity and safety in 29 patients with stage Ib or IIa cervical cancer [58]. The TA-HPV vaccine is a recombinant vaccinia virus that expresses modified forms of the HPV-16 and 18 E6 and E7 oncoproteins. The vaccination was given in two applications ranging from 4-12 weeks apart by dermal scarification and was thought to deliver approximately $2.5 \times 10^{5}$ pfu. The results indicated that after a single vaccination four patients developed HPV specific CTL responses and eight patients developed HPV-specific serological 
responses. Currently, the investigators of this study are continuing examination of this agent in patients with vulvar and vaginal intraepithelial neoplasia (VIN) [11, 28]. Similarly, an MVA-HPV-IL-2 vaccine has been developed that is currently being tested in three phase II clinical trials for patients with VIN, CIN, or cervical cancer. The MVA-HPV-IL2 agent is based on the Modified Virus Ankara (MVA), a non-propagative highly attenuated vaccinia virus strain expressing modified E6 and E7 proteins as well as IL-2 to enhance both specific and non-specific cellular immune responses [6]. In the study involving patients with CIN lesions partial clinical and/or histological responses were observed in five out of 15 patients treated with a high dose of the agent while CIN regression was not observed in 12 patients treated with the low dose. In the study involving patients with cervical cancer two out of 27 patients demonstrated stable disease at 6 months when treated with a low dose of the agent.In the clinical trial involving patients with VIN, clinical results showed no difference in the patients treated with the vaccine compared to the controlled placebo group. However, the low dose of the agent that was utilized for this and the cervical cancer study and given the dose-related effect seen in the CIN2/3 trial; these results were probably due to the low dose used and the advanced stage of the disease of these patients [6]. Despite the encouraging results of these studies, there may be problems involved in immunizing with vaccinia virus. One problem may lie in the fact that a majority of women in the US over the age of 35 have been previously vaccinated with vaccinia virus and women in this age group are at the peak age for cervical cancer acquisition. In the present study, nine patients had prior vaccination with vaccinia virus but none of the four women who developed a CTL response to the HPV antigens had been previously vaccinated. Therefore it is possible that childhood vaccination with vaccinia virus, in an effort to eradicate small pox, may induce a strong and early memory response that may supersede the response to HPV antigens. One way to overcome this challenge may be heterologous boosting. In animal models, it was demonstrated that the existence of neutralizing antibodies to chimeric VLP may prevent boosting of the CMI response in subsequent vaccinations [25]. But this effect can be overcome, by utilizing different chimeric or heterologous VLP in prime-boost vaccination strategies [26]. One recent study showed good protection in mice by priming with recombinant adenylate cyclase toxoid from Bordetella pertussis conjugated to a modified full length HPV-16 E7 protein and then boosting with MVA virus expressing the E7 protein fused to the lysosome-associated LAMP-1 membrane protein [69]. Enhanced CTL immunity was demonstrated in mice by combining TA-HPV, a vaccinia based vaccine containing HPV 16/18 E6/E7, and TA-CIN containing HPV $16 \mathrm{~L} 2, \mathrm{E} 6$ and E7 as a single fusion protein, in a heterologous prime-boost strategy [100]. Recently, this prime boost regime was utilized in a phase II clinical trial [93]. Twenty-nine women with high grade vaginal intraepithelial neoplasia (VIN) received three intramuscular injections of TA-CIN followed by a single dermal scarification with TA-HPV. After twelve weeks 10/27 patients demonstrated increased T cell proliferation responses to HPV antigens and HPV 16 E6 or E7 specific T cells were identified in $11 / 25$ via IFNgamma production in ELISPOT assay. However, only five out of twenty-nine and one out of twenty-nine patients demonstrated partial and complete clinical responses, respectively. This perhaps indicates a need for longer term follow-up in these studies in order to determine the temporal relationship between induction of vaccine induced immune responses and the regression of HPV induced lesions.

Similarly, preclinical studies have been conducted in mice using adenovirus vectors that have demonstrated good protection against HPV-16+ tumor challenges [64]. However, given that vaccinia and adenoviruses are DNA viruses, another potential drawback of using these vectors to deliver HPV E6 and E7 oncogenes in therapeutic vaccines is the potential integration of these oncogenes into the host genome. One method to overcome the potential integration of DNA viruses is to utilize (VLP) from hepatitis B virus to deliver an immunodominant CTL epitope from the HPV-16 E7 protein. Hepatitis B virus VLP are good inducers of both $\mathrm{T}$ and $\mathrm{B}$ cell responses and this strategy prevented the establishment of tumors in mice [33]. Other investigators are attempting to overcome the issues of pre-existing immunity and oncogene integration by using alphavirus vectors in therapeutic vaccine regimens. Alphaviruses such as Sindbis virus, Venezuelan Equine Encephalitis virus (VEE) or Semliki Forest Virus (SFV) are cytopathic RNA viruses that express the RNA of the E6 and E7 oncogenes in the cell's cytosol and thus eliminate the potential integration of these oncogenes into the host cell chromosome. Also there is no preexisting immunity to these viruses in a vast majority of individuals [27,35]. Additionally, Alpha virus vectors have a very wide host range and can infect a variety of different cell types [45] which makes them attractive candidates for delivering antigenic components of vaccines. 
Administration of Sindbis virus replicon particles containing herpes simplex virus type 1 (HSV-1) tegument protein linked to HPV-16E7 resulted in the spread of E7 antigen to neighboring cells and caused a significant increase in the number of E7-specific CD8+T cell precursors and a strong anti-tumor effect against E7-expressing tumors in C57BL/6 mice [20]. Similarly, immunization with recombinant Semliki Forest virus (SFV) encoding a fusion protein of HPV-16 E6 and $\mathrm{E} 7$ resulted in complete elimination of established tumors and induced a long term high level of antigen specific CTL activity in tumor bearing mice [27]. Further advances in using the SFV alpha virus vector may be seen by linking Mycobacterium tuberculosis heat shock protein 70 (Hsp70) to HPV-16 E7. In a recent study, SFV vector containing E7/Hsp70 fusion genes generated significantly higher E7-specific T cellmediated immune responses than SFV vector containing the wild-type E7 gene in vaccinated mice. Furthermore the E7/Hsp70 fusion vaccine demonstrated significant potency against established E7-expressing metastatic tumors in mice [50].

Venezuelan Equine Encephalitis Virus (VEE) replicon particles are unlike other alpha viruses because they have the ability to infect dendritic cells which likely leads to better antigen delivery to naïve $\mathrm{T}$ cells present in the lymph nodes [17]. Recent studies utilizing this agent containing mutated, fused E6 and E7 genes of HPV-16 and demonstrated $100 \%$ protection from tumor challenge in vaccinated mice. Additionally, eradication of established tumors was observed in 90\% of C57/BL6 and HLA-A*0201 transgenic mice during therapeutic vaccination [17]. Although these are preclinical studies, the eradication of tumors in the HLA-A*0201 transgenic mice is significant because these mice bear the most common human leukocyte antigen in the human population. Additionally, this same group of researchers has produced VRP encoding mutated fused E6 and E7 genes of types 18, 45, 31, 33, 52 , and 58 and shown in a recent study that administration of a combination of monovalent HPV containing VRP did not diminish the immune response to type 16 indicating that the simultaneous administration of different monovalent VRP could be useful for therapeutic treatment of lesions infected with multiple HPV types [82]. These encouraging results provide incentive for further examination of this agent in pre-clinical and clinical trials.

Taken together, results from pre-clinical studies of tumor eradication with therapeutic alpha virus vaccination strategies are very promising and are likely to be taken into clinical trials in the near future. Ongoing research in delivery of HPV antigens through viral vectors may include other vectors like flavivirus or Kunjin virus replicons which are non-cytopathic and may allow prolonged expression of inserted genes for presentation to the host's immune system and enhancement of $\mathrm{T}$ cell memory [48].

\section{5. $T$ cell receptor transfer}

One last approach in HPV related tumor therapy that may be utilized in future vaccine trials is the genetic transfer of antigen specific $\mathrm{T}$ cell receptors with high affinity for tumor-associated antigens into patients $\mathrm{T}$ cells. Presumably, this approach will confer the appropriate tumor killing specificity and has the potential to generate a bank of TCR genes with specificity to various viral tumor antigens that may be selected for any patient with tumor cells expressing the appropriate antigen [90,107]. An additional benefit would be that genetically transferred TCR could be tracked by noninvasive imaging or PCR based technologies targeting the unique sequence of the T cell's CDR3 region.

\section{Conclusion}

Because infection with high risk mucosal types of Human Papillomavirus is so closely associated with the development of cervical cancer, several vaccination strategies have been examined in both clinical and preclinical trials for both the prevention of HPV infection and the treatment of pre-existing HPV-related disease. Prophylactic vaccines contain virus-like particles (VLP) that express the HPV viral capsid antigens in a conformational manner and aim to induce neutralizing antibodies to prevent infection with high risk HPV types. Findings from clinical trials with VLP indicate good vaccine efficacy and it is predicted that a prophylactic vaccine for cervical cancer may be available within the next year. However, prophylactic VLP vaccination will have no effect on millions of women already infected with HPV and the millions of women who will become infected before the vaccine is made available. Even after vaccination is implemented it is estimated that a reduction in the incidence of cervical cancer will not be apparent for at least a decade [24]. This stresses the importance of continued therapeutic vaccine development.

Therapeutic vaccination aims to prevent the progression of pre-existing HPV associated lesions or cancers 


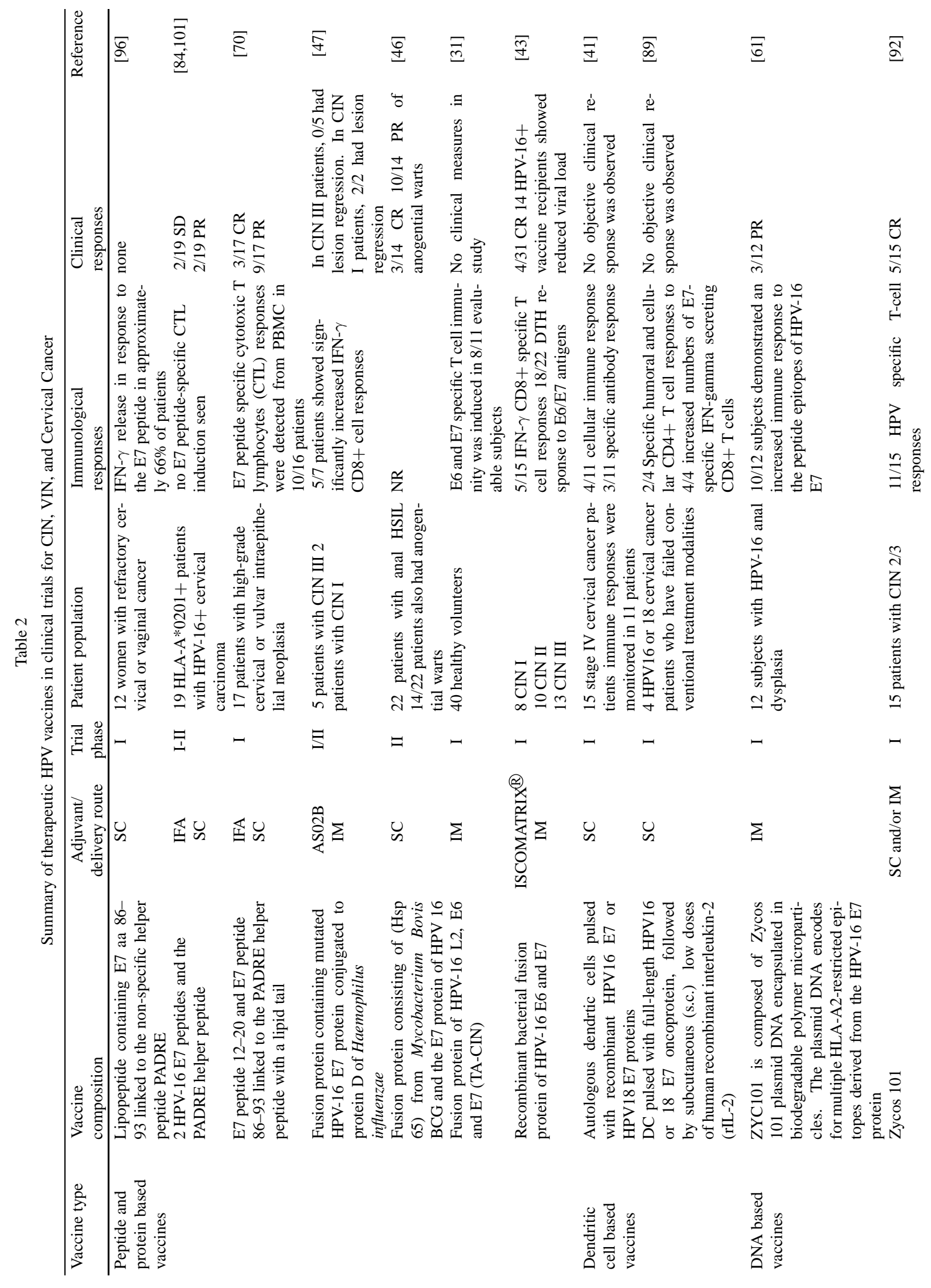




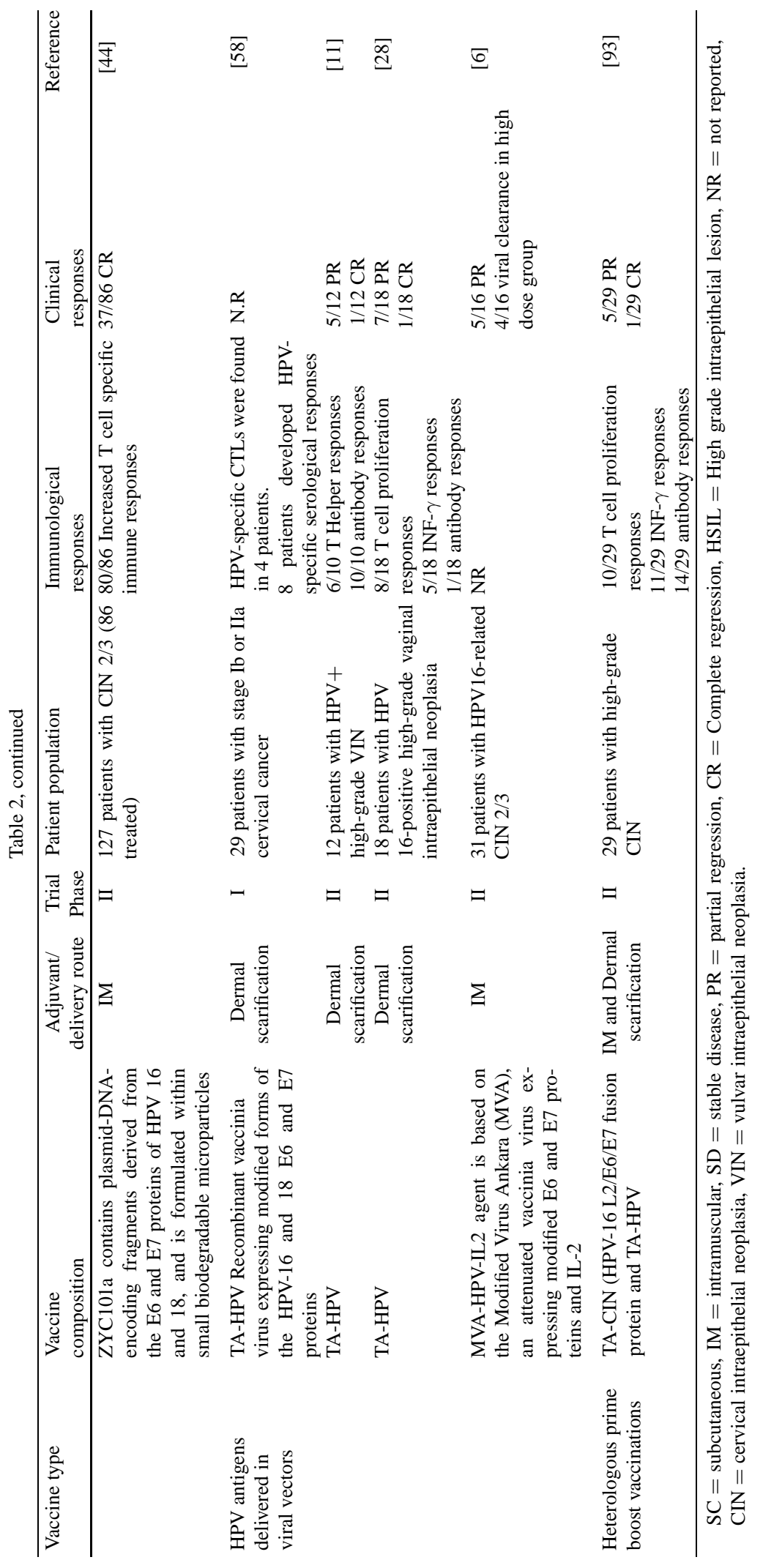


by targeting the E6 or E7 oncogenes because of their role in cellular transformation and continuous expression in cervical cancers. Treating HPV associated lesions with therapeutic vaccination offers an attractive alternative to current clinical procedures. Current therapies like LEEP and cone biopsy procedures can cause damage to the cervix such as stenosis and cervical incompetence. Additionally, these procedures can result in more painful menstrual cycles, excessive bleeding after surgery, secondary infection as the result of surgery, and increased difficultly in taking future Pap smears [10]. Also because these are surgical procedures, when anesthesia is indicated, patient fatality is a remote outcome and these procedures are far more costly than a vaccination which could be administered in a doctor's office. Lastly, given that there is a high recurrence rate with the procedures utilized to treat HPVassociated pre-malignant lesions and the mortality rate from cervical cancer is approximately $40 \%$ [22], elimination of the viral infection via therapeutic vaccination will likely reduce recurrence of HPV-associated pre-malignant lesions causing a reduction in cervical cancers. A summary of current therapeutic vaccination in clinical trials is shown in Table 2.

A majority of clinical trials using therapeutic agents have shown limited efficacy in eradicating established tumors in humans. The lack of clinical outcome seen in these studies may involve the general state of the patients' immune system such that more advanced stage cancer patients tend to have decreased immune function that correlates with stage of disease. Many of the studies examining therapeutic vaccination included patients with advanced stage cancers. Future trends in clinical trials with therapeutic agents will examine patients with early stage cancers and pre-invasive lesions in order to prevent invasive cervical cancer. Meanwhile preclinical studies in this field continue and include the further exploration of peptide or protein vaccination, and the delivery of HPV antigens in DNA-based vaccines or in viral vectors. As long as pre-clinical studies continue to advance in this field, the prospect of therapeutic vaccination to treat existing lesions seem highly likely to be developed in the near future. The result of therapeutic vaccination to treat existing HPV-related disease could include the availability of less invasive and disfiguring treatment options and fewer instances of recurrent or progressive lesions leading to an overall reduction in cervical cancer incidence.

\section{Acknowledgements}

Parts of the studies mentioned in this article were supported through grants NCI R01 CA 74397 and NCI P01 CA 97296 and the V and Whittier Foundations. JA Brinkman is an Achievement Rewards for College Scholars (ARCS) Fellow. WM Kast holds the Walter A. Richter Cancer Research Chair.

\section{References}

[1] http://www.cancer.org., American Cancer Society Inc., 2004.

[2] http://www.stressgen.com, Stressgen Reports HSPE7 Results From Two clinical Trials, 2004

[3] http://www.who.int/vaccine_research/documents/new_ vaccin es/en/index8.html, World health Organization: Human Papillomavirures, 2004.

[4] http://www.centerwatch.com/patient/backgrnd.html, Center Watch Clinical trials listing service, 2006.

[5] http://www.clinicaltrials.gov/ct/info/whatis\#phases, Clinical trials.gov, 2006.

[6] http://www.transgene.fr/us/index.php, Transgene, 2006.

[7] http://www.vitaloptions.org, Vital Options International, 2006.

[8] http://www.who.int/vaccine__research/diseases/viraL cancers/ en/index3.html, World health Organization: Human Papillomavirures, 2006.

[9] M. Alexander, M.L. Salgaller, E. Celis, A. Sette, W.A. Barnes, S.A. Rosenberg and M.A. Steller, Generation of tumor-specific cytolytic $\mathrm{T}$ lymphocytes from peripheral blood of cervical cancer patients by in vitro stimulation with a synthetic human papillomavirus type 16 E7 epitope, Am J Obstet Gynecol 175 (1996), 1586-1593.

[10] Association of Professors of Gynecology and Obstetrics. APGO Educational Series on Women's Health Issues. Advances in the Screening, Diagnosis, and Treatment of Cervical Disease, (2002). 409 12th Street SW, Washington, DC 20024.

[11] P.J. Baldwin, S.H. Van der Burg, C.M. Boswell, R. Offringa, J.K. Hickling, J. Dobson, J.S. Roberts, J.A. Latimer, R.P. Moseley, N. Coleman, M.A. Stanley and J.C. Sterling, Vaccinia-expressed human papillomavirus 16 and 18 e6 and e7 as a therapeutic vaccination for vulval and vaginal intraepithelial neoplasia, Clin Cancer Res 9 (2003), 5205-5213.

[12] J. Banchereau, F. Briere, C. Caux, J. Davoust, S. Lebecque, Y.J. Liu, B. Pulendran and K. Palucka, Immunobiology of dendritic cells, Annu Rev Immunol 18 (2000), 767-811.

[13] J. Banchereau and R.M. Steinman, Dendritic cells and the control of immunity, Nature 392 (1998), 245-252.

[14] M. Barnden, L. Papalia, R. Davis, C. Millar, N. Nikolic, K. O'Brien, L. Wang, A. McKenzie, O. White and I. and Frazer, Antigen-Specific CD4+ and CD8+ T Cell Responses to HPV16 E6E7 ISCOMATRIX ${ }^{\circledR}$ Vaccine in Healthy Volunteers, (2004). Presented at the 21st International Papillomavirus Conference, Mexico City, Mexico.

[15] K.R. Beutner and S. Tyring, Human papillomavirus and human disease, Am J Med 102 (1997), 9-15.

[16] J. Brinkman, X. Xue, M. d. La. Garcia and W.M. Kast, The Efficacy of an Insertional Duplication DNA Vaccine for Eradicating Established Tumors in Mice, Presented at the 21st International Papillomavirus Conference Mexico City, Mexico. 2004. 
[17] M.C. Cassetti, S.P. McElhiney, V. Shahabi, J.K. Pullen, I.C. Le Poole, G.L. Eiben, L.R. Smith and W.M. Kast, Antitumor efficacy of Venezuelan equine encephalitis virus replicon particles encoding mutated HPV16 E6 and E7 genes, Vaccine 22 (2004), 520-527.

[18] S.Y. Chan, H. Delius, A.L. Halpern and H.U. Bernard, Analysis of genomic sequences of 95 papillomavirus types: uniting typing, phylogeny, and taxonomy, J Virol 69 (1995), 3074 3083.

[19] Y.F. Chen, C.W. Lin, Y.P. Tsao and S.L. Chen, Cytotoxic-Tlymphocyte human papillomavirus type 16 E5 peptide with CpG-oligodeoxynucleotide can eliminate tumor growth in C57BL/6 mice, J Virol 78 (2004), 1333-1343.

[20] W.F. Cheng, C.F. Hung, K.F. Hsu, C.Y. Chai, L. He, J.M. Polo, L.A. Slater, M. Ling and T.C. Wu, Cancer immunotherapy using Sindbis virus replicon particles encoding a VP22-antigen fusion, Hum Gene Ther 13 (2002), 553-568.

[21] A. Cid-Arregui, V. Juarez and H. zur Hausen, A synthetic E7 gene of human papillomavirus type 16 that yields enhanced expression of the protein in mammalian cells and is useful for DNA immunization studies, J Virol 77 (2003), 4928-4937.

[22] M.P. Coleman, G. Gatta, A. Verdecchia, J. Esteve, M. Sant, H. Storm, C. Allemani, L. Ciccolallo, M. Santaquilani and F. Berrino, EUROCARE-3 summary: cancer survival in Europe at the end of the 20th century, Ann Oncol 14(Suppl 5) (2003), v128-v149.

[23] J.F. Crish, F. Bone, S. Balasubramanian, T.M. Zaim, T. Wagner, J. Yun, E.A. Rorke and R.L. Eckert, Suprabasal expression of the human papillomavirus type 16 oncoproteins in mouse epidermis alters expression of cell cycle regulatory proteins, Carcinogenesis 21 (2000), 1031-1037.

[24] C.P. Crum, The beginning of the end for cervical cancer? $N$ Engl J Med 347 (2002), 1703-1705.

[25] D.M. Da Silva, D.V. Pastrana, J.T. Schiller and W.M. Kast, Effect of preexisting neutralizing antibodies on the anti-tumor immune response induced by chimeric human papillomavirus virus-like particle vaccines, Virology 290 (2001), 350-360.

[26] D.M. Da Silva, J.T. Schiller and W.M. Kast, Heterologous boosting increases immunogenicity of chimeric papillomavirus virus-like particle vaccines, Vaccine 21 (2003), 3219 3227.

[27] T. Daemen, A. Riezebos-Brilman, L. Bungener, J. Regts, B. Dontje and J. Wilschut, Eradication of established HPV16transformed tumours after immunisation with recombinant Semliki Forest virus expressing a fusion protein of E6 and E7, Vaccine 21 (2003), 1082-1088.

[28] E.J. Davidson, C.M. Boswell, P. Sehr, M. Pawlita, A.E. Tomlinson, R.J. McVey, J. Dobson, J.S. Roberts, J. Hickling, H.C. Kitchener and P.L. Stern, Immunological and clinical responses in women with vulval intraepithelial neoplasia vaccinated with a vaccinia virus encoding human papillomavirus $16 / 18$ oncoproteins, Cancer Res 63 (2003), 6032-6041.

[29] T.D. de Gruijl, H.J. Bontkes, M.J. Stukart, J.M. Walboomers, A.J. Remmink, R.H. Verheijen, T.J. Helmerhorst, C.J. Meijer and R.J. Scheper, T cell proliferative responses against human papillomavirus type $16 \mathrm{E} 7$ oncoprotein are most prominent in cervical intraepithelial neoplasia patients with a persistent viral infection, J Gen Virol 77(Pt 9), (1996), 2183-2191.

[30] T.D. de Gruijl, H.J. Bontkes, J.M. Walboomers, M.J. Stukart, F.S. Doekhie, A.J. Remmink, T.J. Helmerhorst, R.H. Verheijen, M.F. Duggan-Keen, P.L. Stern, C.J. Meijer and R.J. Scheper, Differential T helper cell responses to human papillomavirus type $16 \mathrm{E} 7$ related to viral clearance or persistence in patients with cervical neoplasia: a longitudinal study, Cancer Res 58 (1998), 1700-1706.

[31] A. de Jong, T. O’Neill, A.Y. Khan, K.M. Kwappenberg, S.E. Chisholm, N.R. Whittle, J.A. Dobson, L.C. Jack, J.A. Clair Roberts, R. Offringa, S.H. Van der Burg and J.K. Hickling, Enhancement of human papillomavirus (HPV) type 16 E6 and E7-specific T-cell immunity in healthy volunteers through vaccination with TA-CIN, an HPV16 L2E7E6 fusion protein vaccine, Vaccine 20 (2002), 3456-3464.

[32] T. Doan, K. Herd, I. Ramshaw, S. Thomson and R.W. Tindle, A polytope DNA vaccine elicits multiple effector and memory CTL responses and protects against human papillomavirus 16 E7-expressing tumour, Cancer Immunol Immunother 54 (2005), 157-171.

[33] T. Doan, K. Herd, Y. Woo, H. Netter and R.W. Tindle, Recombinant Hepatitis B Surface Antigen Delivers Protective CTL Responses to HPV16-Associated Neoplastic Disease, Presented at the 22nd International Papillomavirus Conference, Vancouver, Canada. May 2005.

[34] M. Durst, D. Glitz, A. Schneider and H. zur Hausen, Human papillomavirus type 16 (HPV 16) gene expression and DNA replication in cervical neoplasia: analysis by in situ hybridization, Virology 189 (1992), 132-140.

[35] G.L. Eiben, D.M. Da Silva, S.C. Fausch, I.C. Le Poole, M.I. Nishimura and W.M. Kast, Cervical cancer vaccines: recent advances in HPV research, Viral Immunol 16 (2003), 111-121.

[36] E.M. Evans, S. Man, A.S. Evans and L.K. Borysiewicz, Infiltration of cervical cancer tissue with human papillomavirusspecific cytotoxic T-lymphocytes, Cancer Res 57 (1997), 2943-2950.

[37] S.C. Fausch, D.M. Da Silva and W.M. Kast, Differential uptake and cross-presentation of human papillomavirus viruslike particles by dendritic cells and Langerhans cells, Cancer Res 63 (2003), 3478-3482.

[38] S.C. Fausch, D.M. Da Silva, M.P. Rudolf and W.M. Kast, Human papillomavirus virus-like particles do not activate Langerhans cells: a possible immune escape mechanism used by human papillomaviruses, J Immunol 169 (2002), 3242-3249.

[39] S.C. Fausch, L.M. Fahey, D.M. Da Silva and W.M. Kast, Human Papillomavirus Can Escape Immune Recognition through Langerhans Cell Phosphoinositide 3-Kinase Activation, J Immunol 174 (2005), 7172-7178.

[40] M. Favre, N. Ramoz and G. Orth, Human papillomaviruses: general features, Clin Dermatol 15 (1997), 181-198.

[41] A. Ferrara, M. Nonn, P. Sehr, C. Schreckenberger, M. Pawlita, M. Durst, A. Schneider and A.M. Kaufmann, Dendritic cellbased tumor vaccine for cervical cancer II: results of a clinical pilot study in 15 individual patients, J Cancer Res Clin Oncol 129 (2003), 521-530.

[42] I. Frazer, Vaccines for papillomavirus infection, Virus Res 89 (2002), 271-274.

[43] I.H. Frazer, M. Quinn, J.L. Nicklin, J. Tan, L.C. Perrin, P. Ng, V.M. O'Connor, O. White, N. Wendt, J. Martin, J.M. Crowley, S.J. Edwards, A.W. McKenzie, S.V. Mitchell, D.W. Maher, M.J. Pearse and R.L. Basser, Phase 1 study of HPV16-specific immunotherapy with E6E7 fusion protein and ISCOMATRIX adjuvant in women with cervical intraepithelial neoplasia, Vaccine 23 (2004), 172-181.

[44] F. Garcia, K.U. Petry, L. Muderspach, M.A. Gold, P. Braly, C.P. Crum, M. Magill, M. Silverman, R.G. Urban, M.L. Hedley and K.J. Beach, ZYC101a for treatment of high-grade cervical intraepithelial neoplasia: a randomized controlled trial, Obstet Gynecol 103 (2004), 317-326. 
[45] H. Garoff and K.J. Li, Recent advances in gene expression using alphavirus vectors, Curr Opin Biotechnol 9 (1998), 464469.

[46] S.E. Goldstone, J.M. Palefsky, M.T. Winnett and J.R. Neefe, Activity of HspE7, a novel immunotherapy, in patients with anogenital warts, Dis Colon Rectum 45 (2002), 502-507.

[47] S. Hallez, P. Simon, F. Maudoux, J. Doyen, J.C. Noel, A. Beliard, X. Capelle, F. Buxant, I. Fayt, A. C. Lagrost, P. Hubert, C. Gerday, A. Burny, J. Boniver, J.M. Foidart, P. Delvenne and N. Jacobs, Phase I/II trial of immunogenicity of a human papillomavirus (HPV) type $16 \mathrm{E} 7$ protein-based vaccine in women with oncogenic HPV-positive cervical intraepithelial neoplasia, Cancer Immunol Immunother 53 (2004), 642-650.

[48] K.A. Herd, T. Harvey, A.A. Khromykh and R.W. Tindle, Recombinant Kunjin virus replicon vaccines induce protective Tcell immunity against human papillomavirus 16 E7-expressing tumour, Virology 319 (2004), 237-248.

[49] P.M. Howley, Papillomaviruses: The Viruses and Their Replication, in: Fields Virology, B.N. Field, D.M. Knipe and P.M. Howley, eds, Lippincott-Raven, Philadelphia, 1996, pp. 20452076.

[50] K.F. Hsu, C.F. Hung, W.F. Cheng, L. He, L.A. Slater, M. Ling and T.C. Wu, Enhancement of suicidal DNA vaccine potency by linking Mycobacterium tuberculosis heat shock protein 70 to an antigen, Gene Ther 8 (2001), 376-383.

[51] C.H. Huang, S. Peng, L. He, Y.C. Tsai, D.A. Boyd, T.H. Hansen, T.C. Wu and C.F. Hung, Cancer immunotherapy using a DNA vaccine encoding a single-chain trimer of MHC class I linked to an HPV-16 E6 immunodominant CTL epitope, Gene Ther 12 (2005), 1180-1186.

[52] C.F. Hung, W.F. Cheng, L. He, M. Ling, J. Juang, C.T. Lin and T.C. Wu, Enhancing major histocompatibility complex class I antigen presentation by targeting antigen to centrosomes, Cancer Res 63 (2003), 2393-2398.

[53] C.F. Hung, L. He, J. Juang, T.J. Lin, M. Ling and T.C. Wu, Improving DNA vaccine potency by linking Marek's disease virus type 1 VP22 to an antigen, $J$ Virol 76 (2002), 2676-2682.

[54] T. Jakob, J. Ring and M.C. Udey, Multistep navigation of Langerhans/dendritic cells in and out of the skin, J Allergy Clin Immunol 108 (2001), 688-696.

[55] C.A. Janeway, P. Travers, M. Walport and M.J. and Shlomchick, Immunobiology: The Immune System in Health and Disease, p. 4:15, Garland publishing company, York and London 2005.

[56] A.S. Kadish, G.Y. Ho, R.D. Burk, Y. Wang, S.L. Romney, R. Ledwidge and R.H. Angeletti, Lymphoproliferative responses to human papillomavirus (HPV) type 16 proteins E6 and E7: outcome of HPV infection and associated neoplasia, $J$ Natl Cancer Inst 89 (1997), 1285-1293.

[57] W.M. Kast, R.M. Brandt, J.W. Drijfhout and C.J. Melief, Human leukocyte antigen-A2.1 restricted candidate cytotoxic T lymphocyte epitopes of human papillomavirus type $16 \mathrm{E} 6$ and E7 proteins identified by using the processing-defective human cell line T2, J Immunother 14 (1993), 115-120.

[58] A.M. Kaufmann, P.L. Stern, E.M. Rankin, H. Sommer, V. Nuessler, A. Schneider, M. Adams, T.S. Onon, T. Bauknecht, U. Wagner, K. Kroon, J. Hickling, C.M. Boswell, S.N. Stacey, H.C. Kitchener, J. Gillard, J. Wanders, J.S. Roberts and H. Zwierzina, Safety and immunogenicity of TA-HPV, a recombinant vaccinia virus expressing modified human papillomavirus (HPV)-16 and HPV-18 E6 and E7 genes, in women with progressive cervical cancer, Clin Cancer Res 8 (2002), 36763685 .
[59] K.H. Kim, A. Santin, S. Bellone and M. Nakagawa, The HPV 16 E6 52-61 CD8 T Cell Epitope As a Source of Antigen for Dendritic Cell Immunotherapy for Cervical Cancer, Presented at the 22nd International Papillomavirus Conference, Vancouver, Canada. May 2005.

[60] S.W. Kim and J.S. Yang, Human papillomavirus type 16 e5 protein as a therapeutic target, Yonsei Med J 47 (2006), 1-14.

[61] B. Klencke, M. Matijevic, R.G. Urban, J.L. Lathey, M.L. Hedley, M. Berry, J. Thatcher, V. Weinberg, J. Wilson, T. Darragh, N. Jay, M. Da Costa and J.M. Palefsky, Encapsulated plasmid DNA treatment for human papillomavirus 16-associated anal dysplasia: a Phase I study of ZYC101, Clin Cancer Res 8 (2002), 1028-1037.

[62] L.A. Koutsky, D.A. Galloway and K.K. Holmes, Epidemiology of genital human papillomavirus infection, Epidemiol Rev 10 (1988), 122-163.

[63] R.J. Kurman, D.E. Henson, A.L. Herbst, K.L. Noller and M.H. Schiffman, Interim guidelines for management of abnormal cervical cytology. The 1992 National Cancer Institute Workshop, JAMA 271 (1994), 1866-1869.

[64] J. Li, Y. Sun and A. Garen, Immunization and immunotherapy for cancers involving infection by a human papillomavirus in a mouse model, Proc Natl Acad Sci USA 99 (2002), 1623216236.

[65] W.J. Liu, F. Gao, K.N. Zhao, W. Zhao, G.J. Fernando, R. Thomas and I.H. Frazer, Codon modified human papillomavirus type 16 E7 DNA vaccine enhances cytotoxic Tlymphocyte induction and anti-tumour activity, Virology 301 (2002), 43-52.

[66] W.J. Liu, K.N. Zhao, F.G. Gao, G.R. Leggatt, G.J. Fernando and I.H. Frazer, Polynucleotide viral vaccines: codon optimisation and ubiquitin conjugation enhances prophylactic and therapeutic efficacy, Vaccine 20 (2001), 862-869.

[67] D.R. Lowy and P.M. Howley, Papillomaviruses, in: Fields Virology, D.M. Knipe, P.M. Howley, D.E. Griffin, R.A. Lamb, M.A. Martin, B. Roizman and S.E. Straus, eds, Lippincott Williams \& Wilkins, 2001

[68] J.C. Luxton, A.J. Rowe, J.C. Cridland, T. Coletart, P. Wilson and P.S. Shepherd, Proliferative T cell responses to the human papillomavirus type $16 \mathrm{E} 7$ protein in women with cervical dysplasia and cervical carcinoma and in healthy individuals, $J$ Gen Virol 77(Pt 7), (1996), 1585-1593.

[69] J. Mackova, J. Stasikova, L. Kutinova, J. Masin, P. Hainz, M. Simsova, P. Gabriel, P. Sebo and S. Nemeckova, Prime/boost immunotherapy of HPV16-induced tumors with E7 protein delivered by Bordetella adenylate cyclase and modified vaccinia virus Ankara, Cancer Immunol Immunother 55 (2006), 39-46.

[70] L. Muderspach, S. Wilczynski, L. Roman, L. Bade, J. Felix, L.A. Small, W.M. Kast, G. Fascio, V. Marty and J. Weber, A phase I trial of a human papillomavirus (HPV) peptide vaccine for women with high-grade cervical and vulvar intraepithelial neoplasia who are HPV 16 positive, Clin Cancer Res 6 (2000), 3406-3416.

[71] K. Munger, The molecular biology of cervical cancer, J Cell Biochem Suppl 23 (1995), 55-60.

[72] K. Munger, A. Baldwin, K.M. Edwards, H. Hayakawa, C.L. Nguyen, M. Owens, M. Grace and K. Huh, Mechanisms of human papillomavirus-induced oncogenesis, J Virol 78 (2004), 11451-11460.

[73] M. Nimako, A.N. Fiander, G.W. Wilkinson, L.K. Borysiewicz and S. Man, Human papillomavirus-specific cytotoxic T lymphocytes in patients with cervical intraepithelial neoplasia grade III, Cancer Res 57 (1997), 4855-4861. 
[74] P. Ohlschlager, M. Pes, W. Osen, M. Durst, A. Schneider, L. Gissmann and A.M. Kaufmann, An improved rearranged Human Papillomavirus Type 16 E7 DNA vaccine candidate (HPV-16 E7SH) induces an E7 wildtype-specific $T$ cell response, Vaccine, 2006.

[75] W. Osen, T. Peiler, P. Ohlschlager, S. Caldeira, S. Faath, N. Michel, M. Muller, M. Tommasino, I. Jochmus and L. Gissmann, A DNA vaccine based on a shuffled E7 oncogene of the human papillomavirus type 16 (HPV 16) induces E7-specific cytotoxic T cells but lacks transforming activity, Vaccine 19 (2001), 4276-4286.

[76] S. Peng, H. Ji, C. Trimble, L. He, Y.C. Tsai, J. Yeatermeyer, D.A. Boyd, C.F. Hung and T.C. Wu, Development of a DNA vaccine targeting human papillomavirus type 16 oncoprotein E6, J Virol 78 (2004), 8468-8476.

[77] S. Peng, T.W. Kim, J.H. Lee, M. Yang, L. He, C.F. Hung and T.C. Wu, Vaccination with dendritic cells transfected with BAK and BAX siRNA enhances antigen-specific immune responses by prolonging dendritic cell life, Hum Gene Ther $\mathbf{1 6}$ (2005), 584-593.

[78] S. Peng, C. Trimble, H. Ji, L. He, Y.C. Tsai, B. Macaes, C.F. Hung and T.C. Wu, Characterization of HPV-16 E6 DNA vaccines employing intracellular targeting and intercellular spreading strategies, J Biomed Sci 12 (2005), 689-700.

[79] M. Pes, P. Ohlschlager, L. Gissman, A. Schneider, M. Durst and A.M. Kaufman, Dendritic Cells Transfected by a Rearranged HPV16E7 DNA Vaccine Induce in Vitro E7 WildtypeSpecific Human T Cells. Presented at the 22nd International Papillomavirus Conference, Vancouver, Canada. May 2005.

[80] N.C. Popescu and J.A. DiPaolo, Preferential sites for viral integration on mammalian genome, Cancer Genet Cytogenet 42 (1989), 157-171.

[81] X. Preville, D. Ladant, B. Timmerman and C. Leclerc, Eradication of Established Tumors by Vaccination With Recombinant Bordetella Pertussis Adenylate Cyclase Carrying the $\mathrm{Hu}$ man Papillomavirus 16 E7 Oncoprotein, Presented at the 22nd International Papillomavirus Conference, Vancouver, Canada. May 2005.

[82] J.K. Pullen, S.P. McElhiney, M. Lee, W. Al-Rimawi, J. Li, A. Ota-Setlik, R.J. Natuk, J. Kowalski, D.M. Da Silva and W.M. Kast, Development of a Multivalent Vaccine for Therapeutic Immunization Against HPV-Associated Diseases, Presented at the 22nd International Papillomavirus Conference, Vancouver, Canada. 2005.

[83] M.E. Ressing, A. Sette, R.M. Brandt, J. Ruppert, P.A. Wentworth, M. Hartman, C. Oseroff, H.M. Grey, C.J. Melief and W.M. Kast, Human CTL epitopes encoded by human papillomavirus type $16 \mathrm{E} 6$ and $\mathrm{E} 7$ identified through in vivo and in vitro immunogenicity studies of HLA-A*0201-binding peptides, J Immunol 154 (1995), 5934-5943.

[84] M.E. Ressing, W.J. van Driel, R.M. Brandt, G.G. Kenter, J.H. de Jong, T. Bauknecht, G.J. Fleuren, P. Hoogerhout, R. Offringa, A. Sette, E. Celis, H. Grey, B.J. Trimbos, W.M. Kast and C.J. Melief, Detection of Thelper responses, but not of human papillomavirus-specific cytotoxic T lymphocyte responses, after peptide vaccination of patients with cervical carcinoma, J Immunother 23 (2000), 255-266.

[85] M.E. Ressing, W.J. van Driel, E. Celis, A. Sette, M.P. Brandt, M. Hartman, J.D. Anholts, G.M. Schreuder, W.B. ter Harmsel, G.J. Fleuren, B.J. Trimbos, W.M. Kast and C.J. Melief, Occasional memory cytotoxic T-cell responses of patients with human papillomavirus type 16-positive cervical lesions against a human leukocyte antigen-A *0201-restricted E7-encoded epitope, Cancer Res 56 (1996), 582-588.
[86] A. Ribas, L.H. Butterfield, J.A. Glaspy and J.S. Economou, Current developments in cancer vaccines and cellular immunotherapy, J Clin Oncol 21 (2003), 2415-2432.

[87] M.P. Rudolf, S. Man, C.J. Melief, A. Sette and W.M. Kast, Human T-cell responses to HLA-A-restricted high binding affinity peptides of human papillomavirus type 18 proteins E6 and E7, Clin Cancer Res 7 (2001), 788s-795s.

[88] R.B. Salit, W.M. Kast and M.P. Velders, Ins and outs of clinical trials with peptide-based vaccines, Front Biosci 7 (2002), e204-e213.

[89] A.D. Santin, S. Bellone, M. Palmieri, A. Ravaggi, C. Romani, R. Tassi, J.J. Roman, A. Burnett, S. Pecorelli and M.J. Cannon, HPV16/18 E7-pulsed dendritic cell vaccination in cervical cancer patients with recurrent disease refractory to standard treatment modalities, Gynecol Oncol 100 (2006), 469-478.

[90] K.B. Scholten, M.W. Schreurs, J.J. Ruizendaal, E.W. Kueter, D. Kramer, S. Veenbergen, C.J. Meijer and E. Hooijberg, Preservation and redirection of HPV16E7-specific T cell receptors for immunotherapy of cervical cancer, Clin Immunol 114 (2005), 119-129.

[91] K.V. Shah and P.M. and Howley, Papillomaviruses, in: Fields Virology, D.M. Knipe, P.M. Howley, D.E. Griffin, R.A. Lamb, M.A. Martin, B. Roizman and S.E. Straus, eds, Lippincott Williams \& Wilkins, 1990.

[92] E.E. Sheets, R.G. Urban, C.P. Crum, M.L. Hedley, J.A. Politch, M.A. Gold, L.I. Muderspach, G.A. Cole and P.A. Crowley-Nowick, Immunotherapy of human cervical highgrade cervical intraepithelial neoplasia with microparticledelivered human papillomavirus 16 E7 plasmid DNA, Am J Obstet Gynecol 188 (2003), 916-926.

[93] L.J. Smyth, M.I. Van Poelgeest, E.J. Davidson, K.M. Kwappenberg, D. Burt, P. Sehr, M. Pawlita, S. Man, J.K. Hickling, A.N. Fiander, A. Tristram, H.C. Kitchener, R. Offringa, P.L. Stern and S.H. Van der Burg, Immunological responses in women with human papillomavirus type 16 (HPV-16)associated anogenital intraepithelial neoplasia induced by heterologous prime-boost HPV-16 oncogene vaccination, Clin Cancer Res 10 (2004), 2954-2961.

[94] S.A. Southern and C.S. Herrington, Differential cell cycle regulation by low- and high-risk human papillomaviruses in lowgrade squamous intraepithelial lesions of the cervix, Cancer Res 58 (1998), 2941-2945.

[95] R.M. Steinman, The dendritic cell system and its role in immunogenicity, Anпи Rev Immunol 9 (1991), 271-296.

[96] M.A. Steller, K.J. Gurski, M. Murakami, R.W. Daniel, K.V. Shah, E. Celis, A. Sette, E.L. Trimble, R.C. Park and F.M. Marincola, Cell-mediated immunological responses in cervical and vaginal cancer patients immunized with a lipidated epitope of human papillomavirus type 16 E7, Clin Cancer Res 4 (1998), 2103-2109.

[97] S.K. Tyring, Human papillomavirus infections: epidemiology, pathogenesis, and host immune response, J Am Acad Dermatol 43 (2000), S18-S26.

[98] A. Vambutas, J. Devoti, M. Nouri, J. Drijfhout, G. Lipford, V. Bonagura, S. van der Burg and C.J. Melief. Therapeutic Vaccination With Papillomavirus E6 and E7 Long Peptides Results in the Control of Both Established Virus-Induced Lesions and Latently Infected Sites in a Pre-Clinical Cottontail Rabbit Papillomavirus Model. Presented at the 22nd International Papillomavirus Conference, Vancouver, Canada. May 2005.

[99] S.H. Van der Burg, A. de Jong, M.J. Welters, R. Offringa and C.J. Melief, The status of HPV16-specific T-cell reactivity in 
health and disease as a guide to HPV vaccine development, Virus Res 89 (2002), 275-284.

[100] S.H. Van der Burg, K.M. Kwappenberg, T. O'Neill, R.M Brandt, C.J. Melief, J.K. Hickling and R. Offringa, Preclinical safety and efficacy of TA-CIN, a recombinant HPV16 L2E6E7 fusion protein vaccine, in homologous and heterologous prime-boost regimens, Vaccine 19 (2001), 3652-3660.

[101] W.J. van Driel, M.E. Ressing, G.G. Kenter, R.M. Brandt, E.J. Krul, A.B. van Rossum, E. Schuuring, R. Offringa, T. Bauknecht, A. Tamm-Hermelink, P.A. van Dam, G.J. Fleuren, W.M. Kast, C.J. Melief and J.B. Trimbos, Vaccination with HPV 16 peptides of patients with advanced cervical carcinoma: clinical evaluation of a phase I-II trial, Eur J Cancer 35 (1999), 946-952.

[102] M.P. Velders, S. Weijzen, G.L. Eiben, A.G. Elmishad, P.M. Kloetzel, T. Higgins, R.B. Ciccarelli, M. Evans, S. Man, L. Smith and W.M. Kast, Defined flanking spacers and enhanced proteolysis is essential for eradication of established tumors by an epitope string DNA vaccine, J Immunol 166 (2001), 5366-5373.

[103] M. von Knebel Doeberitz, C. Rittmuller, F. Aengeneyndt, P. Jansen-Durr and D. Spitkovsky, Reversible repression of papillomavirus oncogene expression in cervical carcinoma cells: consequences for the phenotype and E6-p53 and E7-pRB interactions. J Virol 68, (1994), 2811-2821.

[104] J.M. Walboomers, M.V. Jacobs, M.M. Manos, F.X. Bosch, J.A. Kummer, K.V. Shah, P.J. Snijders, J. Peto, C.J. Meijer and N. Munoz, Human papillomavirus is a necessary cause of invasive cervical cancer worldwide, J Pathol 189 (1999), 12-19.

105] D.E. Warrino, W.C. Olson, W.T. Knapp, M.I. Scarrow, L.J. D'Ambrosio-Brennan, R.S. Guido, R.P. Edwards, W.M. Kast and W.J. Storkus, Disease-stage variance in functional CD4(+) T-cell responses against novel pan-human leukocyte antigen-D region presented human papillomavirus-16 E7 epitopes, Clin Cancer Res 10 (2004), 3301-3308.

[106] D.E. Warrino, W.C. Olson, M.I. Scarrow, L.J. D’AmbrosioBrennan, R.S. Guido, D.M. Da Silva, W.M. Kast and W.J. Storkus, Human papillomavirus L1L2-E7 virus-like particles partially mature human dendritic cells and elicit E7-specific T-helper responses from patients with cervical intraepithelial neoplasia or cervical cancer in vitro, Hum Immunol 66 (2005), $762-772$.

[107] S. Xue, R. Gillmore, A. Downs, A. Tsallios, A. Holler, L. Gao, V. Wong, E. Morris and H.J. Stauss, Exploiting T cell receptor genes for cancer immunotherapy, Clin Exp Immunol 139 (2005), 167-172.

[108] H. zur Hausen, Papillomaviruses and cancer: from basic studies to clinical application, Nat Rev Cancer 2 (2002), 342350.

[109] S. Zwaveling, S.C. Ferreira Mota, J. Nouta, M. Johnson, G.B. Lipford, R. Offringa, S.H. Van der Burg and C.J. Melief, Established human papillomavirus type 16-expressing tumors are effectively eradicated following vaccination with long peptides, J Immunol 169 (2002), 350-358. 


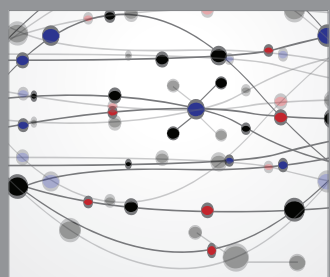

The Scientific World Journal
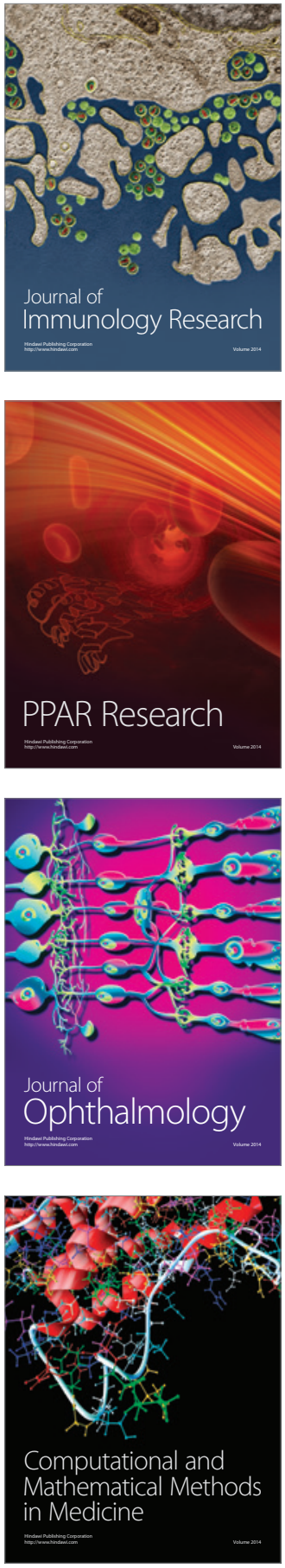

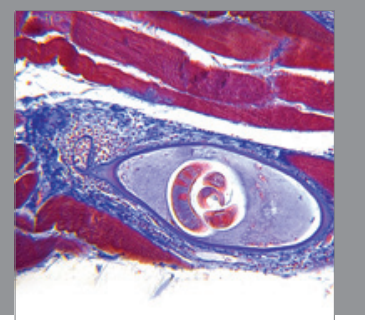

Gastroenterology

Research and Practice
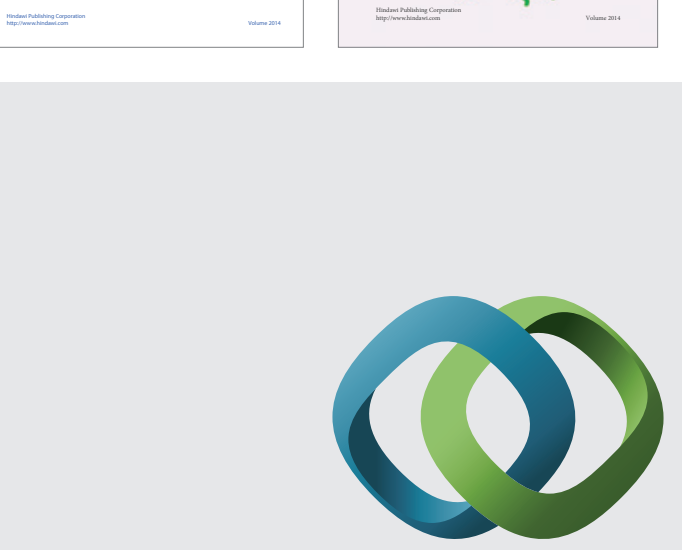

\section{Hindawi}

Submit your manuscripts at

http://www.hindawi.com
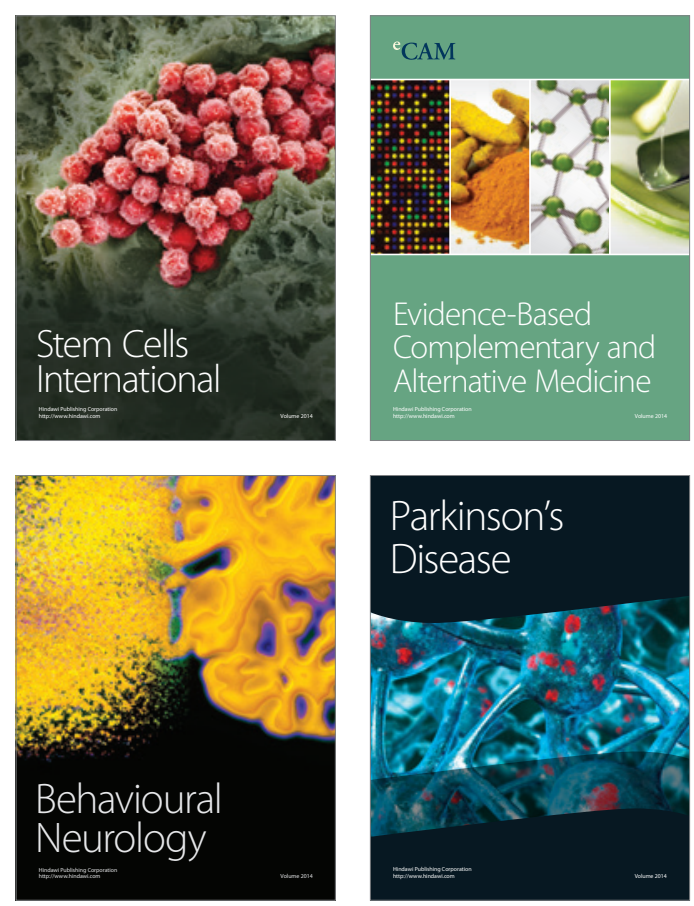

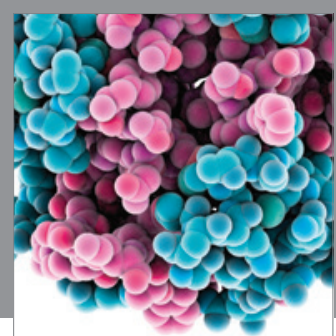

Journal of
Diabetes Research

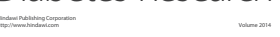

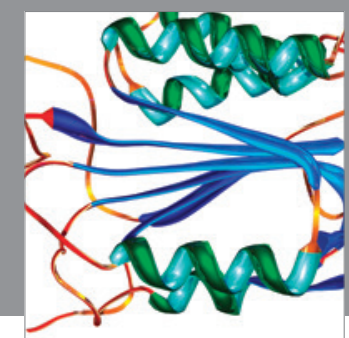

Disease Markers
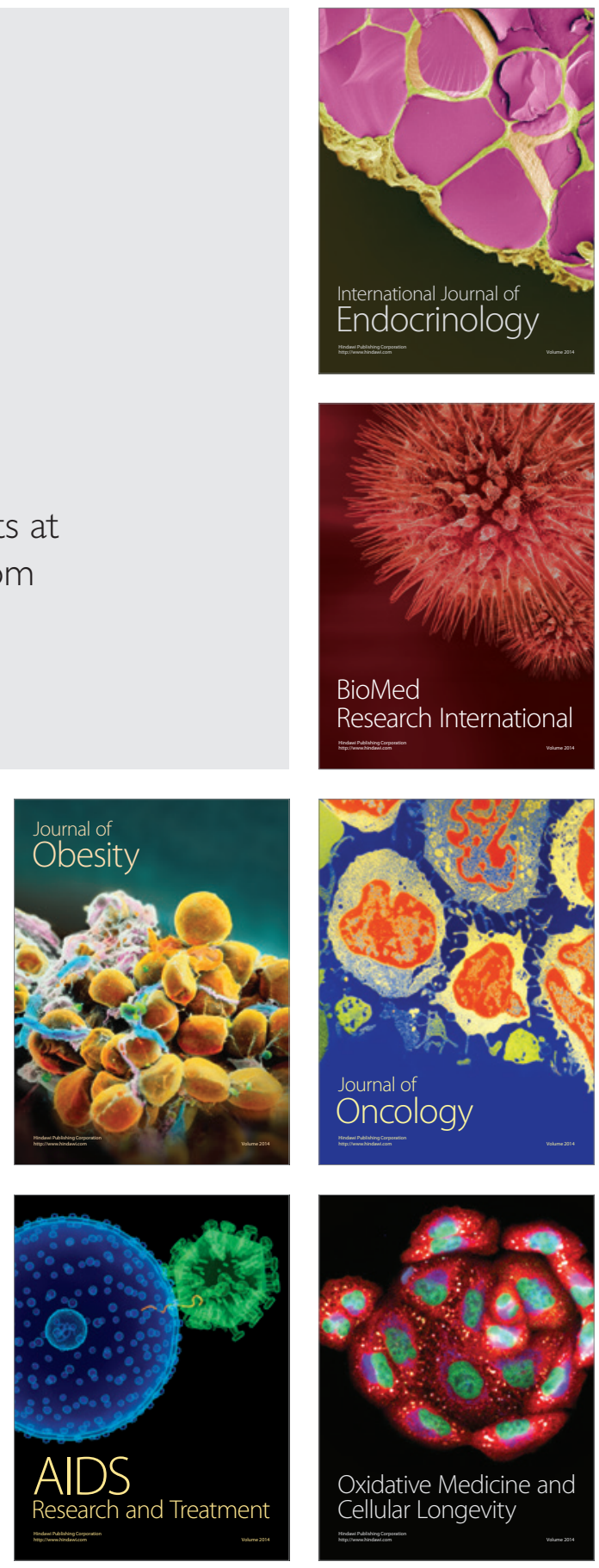